\title{
USING GCMS TO FIND OUT THE VOLATILE COMPONENTS IN THE AROMA OF THREE DIFFERENT COMMERCIAL FRUITS IN CHINA
}

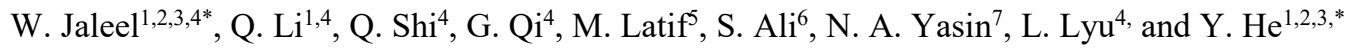 \\ ${ }^{1}$ Key Laboratory of Bio-Pesticide Innovation and Application, Guangdong Province, Guangzhou 510640, China \\ ${ }^{2}$ Engineering Research Center of Biological control, Ministry of Education, Guangzhou 510640, China \\ ${ }^{3}$ Department of Entomology, College of Agriculture, South China Agricultural University, Guangzhou 510642, \\ Guangdong Province, China. \\ ${ }^{4}$ Plant Protection Research Institute, Guangdong Academy of Agricultural Sciences, Guangzhou, China. \\ ${ }^{5}$ Department of Zoology Division of Science and Technology, University of Education Lahore. \\ ${ }^{6}$ Hubei Insect Resources Utilization and Sustainable Pest Management Key Laboratory, College of Plant Science and \\ Technology, Huazhong Agricultural University, Wuhan 430070, P. R. China. \\ ${ }^{7}$ RO (II) Wing, New Campus, University of the Punjab, Lahore-54590, Punjab, Pakistan. \\ *Corresponding author's email: yrhe@scau.edu.cn,waqar4me@yahoo.com
}

\begin{abstract}
The agricultural sector is an essential source of income and food for humans. Fruits are important sources of nutrients, vitamins, essential elements, and as well as the source of income for humans. Volatile components make the aroma of fruit and fruit species and cultivars. However, the knowledge and information about volatile components or volatile profiles are essential, because these aroma components make fruit delicious to humans and as well as attract or repel insect pests. And the identification of volatile components from fruits is very important to a better understanding of the impact of climatic conditions. To the best authors knowledge, in this study, we reported the first time volatile profile of unidentified cultivar of mango (Mangifera indica L. Hanana Datai Nong Mang), guava (Psidium guajava Linn. China Pear), and banana (Musa acuminata L. Dwarf banana or Fen Jiao) fruits and these fruits are commercially selling and growing in China. The Headspace Solid-phase Microextraction (HS-SPME) and porapak Q coupled with gas chromatography-mass spectrometry analysis (GC-MS) were used to identify the volatile profiles of each fruit cultivar. A total of 10, 15, and 23 volatile components/compounds were identified from mango, guava, and banana fruits, respectively. The major constitution of volatile components obtained from mango, guava, and banana was 3-carene, caryophyllene, and cycloheptasiloxane, tetradecamethyl-.
\end{abstract}

Key words; Banana, 3-carene, caryophyllene, cycloheptasiloxane, components, tetradecamethyl-, GC-MS, guava, mango, volatile components.

https://doi.org/10.36899/JAPS.2021.1.0204

Published online August 26, 2020

\section{INTRODUCTION}

The agricultural sector is an important source of food, e.g., fruits, vegetables, and crops, as well as income for humans (FAO, 2016; FAO, 2017). Mango (Mangifera indica L), guava (Psidium guajava Linn), and banana (Musa spp) are most important tropical, sub-tropical, and temperate fruits and kept most important nutrients, vitamins, essential elements that are good for humans health (Paniandy et al., 2000; Joseph and Priya, 2011; Gautam and Gotame, 2020). Each fruit has its volatile components that have a great impact on making the aroma of fruits. The attraction of insect pests to volatiles that is elicited from their host, e.g., fruits have been studied (Cruz-López et al., 2006; Siderhurst and Jang, 2006; Alagarmalai et al., 2009; El-Sayed et al., 2009; Siderhurst and Jang, 2010; Biasazin et al., 2014; Jayanthi et al., 2014; Jaleel et al., 2019; Ali et al., 2020; Jaleel et al., 2020).
Mango fruits are also called "King of fruits." Mango fruits have rich nutrient sources as well as a livelihood for millions of people (Mitra, 2014; Sial et al., 2015). Volatiles components from a different cultivar of mango fruits have been identified in Africa, Australia, India, United States, Sri Lanka, and Venezuela (Rodríguez et al., 2013; Souza et al., 2018). Different mango cultivars still have not been used on a commercial level that exhibiting a wide range of flavors (MacLeod and Pieris, 1984; Damodaram et al., 2015; Galal et al., 2017). In the Coche mangoes, the predominant volatile components were 3-carene, b-selinene, terpinolene, and limonene (Malo et al., 2012; Xiao-Wei et al., 2016). 3carene has been reported in the aroma of mango fruits (Tamura et al., 2000; Vithana et al., 2018). 3-carene, acetic, butyric, hexanoic acids, and ethyl 3hydroxybutyrate have been reported from mango fruits (Sakho et al., 1985; Kondo, 2018). Thirteen mango volatiles components were detected, e.g., acetaldehyde, 
acetone, methanol, ethanol, a-pinene, caryophyllene, 3carene, b-pinene, myrcene, limonene, terpinolene, acopaene, and r-cymene (Baldwin et al., 1999; Pino and Mesa, 2006; Shaw, 2017).

Guava fruits have been originated from tropical America (Shen et al., 2008; Singh et al., 2018). Guava fruits have volatile aromatic components, e.g., antioxidants, vitamins, lutein, zeaxanthine, and lycopene. Leaves, shoots, and fruits of guava are useful in medicine for the treatment of various human diseases (Zahoor et al., 2017). Polysaccharides, vitamins, minerals, enzymes, essential oils, proteins (Jordán et al., 2001; Deo and Shastri, 2003; Bodini et al., 2019), sesquiterpenoid, triterpenoid acids, alkaloids, glycosides, steroids, tannins, and saponins are essential compounds of guava fruit (Xu et al., 2017).

Bananas are very important source of human diets and income. Genus Musa. Linnaeus has more than 100 common names around the world (Arvanitoyannis and Mavromatis, 2009; Asif and Kaur, 2018). Jordán et al. (2001) have reported 43 volatile components and prominent were 1-methyl butyl isobutyrate 2,3-butanediol diacetate, 2-hydroxy-3-methylethylbutyrate, methyl butyrate, ethyl 3-hydroxyhexanoate, 2-pentanol acetate, Isoamyl acetate, 2-methyl-1-propanol, 3-methyl-1butanol, 3-methylbutanal, acetal, isobutyl acetate, hexanal, ethyl butyrate, 2-heptanol, and butyl butyrate. Banana fruits have full acceptance, among other fruits, due to nutritional value (Zhu et al., 2018). More than 350 volatile components/compounds have been identified in the aroma of banana fruits, e.g., esters, alcohols, and carbonyl compounds are the most important volatile components (Girard et al., 1997; Jordán et al., 2001; Pino and Febles, 2013; Zhu et al., 2018). Volatile components, e.g., 3-methyl butyl acetate, isoamyl butanoate, and isoamyl isovalerate, were reported as key components of banana "fruity" odor (Schwab et al., 2008). Identification of phytochemicals is the most important study; because phytochemicals play an important role in attraction or repellant of insects (Forister et al., 2015; Jaleel et al., 2018b).

Volatile or aromatic compounds are important for the quality of fruit and can vary among fruit cultivars (Zhu et al., 2018). Information about volatile components or volatile profile is very important because these aroma components are responsible for fruit quality. And the identification of volatile components from fruits is very important to a better understanding of the impact of environmental conditions. In this study, we reported first time volatile profile of unidentified cultivar of mango (Mangifera indica L. Hanana Datai Nong Mang), guava (Psidium guajava Linn. China Pear), and banana (Musa acuminata L. Dwarf banana or Fen Jiao) fruits and these fruits are commercially selling and growing in China.

\section{MATERIALS AND METHODS}

Fruit: Ripe mango (M. indica: Hanana Datai Nong Mang: guava ( $P$. guajava: China Pear: and banana ( $M$. acuminate: Dwarf banana or Fen Jiao) were purchased from the orchard located in Guangzhou, Guangdong, China. Fruits were washed and dried and then used for experimental purposes (Figure 1).

Fruits characteristics: Based on detailed discussion with a sailor, all fruits were bagged in the field before the stage of ripening to avoid the attack of wild insect pests. Total soluble solids (TSS or Brix) of fruits were measured using handheld pocket refractometer pal-1 (ATAGO, PR-101a, Brix 0-45\%, Tokyo Tech. Japan) (Figure 2a), and the pericarp toughness or firmness of fruits were measured by a TMS-Pro texture analyzer (FTC-TV, USA) with probe (1 $\mathrm{mm}$ diameter) (Jaleel et al., 2018c) (Figure 2b). Measurements were taken and recorded at three different locations on each fruit. Fifteen replications were done for each fruit.

Volatiles collection: Collection of volatiles from the surface of mango, guava, and banana were done by two ways as solid-phase micro-extraction (SPME) and porapak Q (80-100 mesh; Alltech, Deerfield, IL, USA) in the laboratory of Plant Protection Research Institute, Guangdong Academy of Agricultural Science, Guangzhou, China.

The solid-phase micro-extraction (SPME) fiber (assembly $100 \mu \mathrm{m}$ PDMS, fused silica $24 \mathrm{Ga}$, the manual holder $3 \mathrm{pk}$ red) was used for the collection of fruits volatiles compounds, First, the SPME fiber was preconditioned in a $\mathrm{GC}$ injector $\left(250^{\circ} \mathrm{C}\right)$ for $30 \mathrm{~min}$. A fruit was placed in a $500 \mathrm{ml}$ clear straight-sided jar with a screw-top lid fitted with a Teflon liner. The SPME needle inserted through a small hole in the lid, and the fiber exposed till $1 \mathrm{~h}$ (Figure 3 ), the fiber was removed from the jar and then immediately inserted into the GC injection port to desorb volatiles. The whole procedure was repeated fifteen times for each fruit (mango, guava, and banana).

Collection of volatiles from mango, guava, and banana was done using porapak Q. Before collection of samples, the porapak Q tube preconditioned at $280{ }^{\circ} \mathrm{C}$ for $30 \mathrm{~min}$ and washed with dichloromethane, then dried under charcoal purified nitrogen. Porapak Q was connected with an air pump, that have connection with an air flow meter (AFM) (for controlling the flow of air through the system), water bottle, charcoal, plastic bag (Oven bag, Turkey size, $482 \times 596 \mathrm{~mm}$ ), and air sucker (Figure 4). In order to activate the charcoal, it was preheated at $200{ }^{\circ} \mathrm{C}$ for $3 \mathrm{hrs}$. The charcoal flask was followed by oven bag containing a specified amount (2 $\mathrm{kg}$ ) of the sample (fruits). Air after passing through the oven bag then passed through the porapak Q, the absorbent material inside the porapak Q. The adsorption 
of the volatile compounds was done after $24 \mathrm{hrs}$. Volatiles eluted from the adsorbents of porapak $\mathrm{Q}$ with the help of $1 \mathrm{ml} \mathrm{CH}_{2} \mathrm{Cl}_{2}$ and then stored at $-80{ }^{\circ} \mathrm{C}$ in the refrigerator. With the help of a microsyringe (1000 microlitres) the volatile compounds/components were collected from the porapak Q into the glass tube (capacity $2 \mathrm{ml}$ ). The whole procedure was repeated fifteen times for each fruit. The $0.1 \mu \mathrm{l}$ was taken from a sample of fruits and used for the analysis.

Gas chromatography-mass spectrometry (GC/MS): The GC-MS quantitative and qualitative analysis were performed on an Agilent $7890 \mathrm{~N}$ gas chromatograph, coupled with an Agilent $5975 \mathrm{C}$ mass selective detector (GC-MS) that equipped with an HP-5 MS, capillary column $(30 \mathrm{~m} \times 0.25 \mathrm{~mm}$ ID, film thickness $0.25 \mu \mathrm{m}$, Agilent Technologies, USA). The temperature was programmed from 45 (held for $1 \mathrm{~min}$ ) to $280^{\circ} \mathrm{C}$ at $10^{\circ} \mathrm{C} /$ min. The solvent delay was kept $5 \mathrm{~min}$, while the injector temperature was used at $250{ }^{\circ} \mathrm{C}$ and helium gas was used as the carrier. Electron ionization mass spectra were recorded from m / z $29{ }^{\circ} \mathrm{C}$ to $280{ }^{\circ} \mathrm{C}$ at $70 \mathrm{eV}$ with iron source temperature at $230{ }^{\circ} \mathrm{C}$

Compounds identification: Quantitative and qualitative constituents' analysis of fruits were done on the basis of their retention times $(R t)$ and mass spectra in the computer library (NIST. 11). The quantity of each fruit components was compared by measurements as using area of the peak.

\section{RESULTS}

Fruits characteristics: Characteristics like length $(\mathrm{cm})$, width $(\mathrm{cm})$, thickness $(\mathrm{cm})$, total soluble solids (TSS) or brix firmness/hardness $(\mathrm{N})$ of and mango, guava, and banana, are shown in table 1 . The pericarp toughness of mango fruit was lower than those of the other two tested fruits (banana and guava). While the Brix level of mango was higher than those of the other two tested fruits (Figure 5).

GC-MS analyses of mango: The volatile components of mango were given in table 1 . Overall, $99.99 \%$ of components were identified. The major dominating volatile/aromatic components were 3-carene, $\alpha$-pinene, and butyl caprylate, which accounts $(86.62 \%)$ of total components. While other minor constitutes, which makeup the balance was filled with following components e.g. cyclopentasiloxane decamethyl, cyclohexasiloxane dodecamethyl-, hexanoic acid, 3hexenyl ester, (Z: 1-tridecene, tetradecane, humulene, and l-limonene (Table 1).

GC-MS analyses of guava: The GC-MS analyses of volatile components of guava are presented in table 2 . Overall, $99.99 \%$ of components were recognized. The major dominating components were caryophyllene, $\alpha$ pinene, gamma. -terpinene, and $\alpha$-copaene, which accounts $(56.90 \%)$ of total constitutes. While other minor constitutes, which make up the balance was filled with following components e.g. Eucalyptol, cyclohexasiloxane dodecamethyl-, aromandendrene, humulene, cycloheptasiloxane tetradecamethyl-., cis- $\alpha-$ bisabolene, epizonarene, phenol, 2,2'-methylenebis[6(1,1-dimethylethyl)-4-methyl-, diisooctyl phthalate, eicosane, and octadecanal (Table 2).

Table 1. Volatile components from the mango.

\begin{tabular}{cccccc}
\hline Peak \# & RT $^{\mathbf{a}}($ Paniandy $\boldsymbol{e t ~ a l .})$ & Relative $\%$ & Components name $^{\mathbf{b}}$ & KI(Exp) $^{\mathbf{c}}$ & $\mathbf{A I}_{(\mathbf{E x p})^{\mathbf{d}}}$ \\
\hline 1 & 6.778 & 77.07666 & 3-Carene & 984 & 986 \\
2 & 8.342 & 4.253949 & a-pinene & 1003 & 1003 \\
3 & 9.449 & 2.823219 & Cyclopentasiloxane, decamethyl & 1121 & 1122 \\
4 & 12.142 & 2.687374 & Cyclohexasiloxane, dodecamethyl- & 1290 & 1291 \\
5 & 12.642 & 0.19506 & Hexanoic acid, 3-hexenyl ester, $(Z)$ & 1397 & 1397 \\
6 & 13.232 & 5.314137 & Butyl caprylate & 1459 & 1460 \\
7 & 13.942 & 1.147518 & 1-Tridecene & 1559 & 1559 \\
8 & 14.156 & 2.928431 & Tetradecane & 1650 & 1651 \\
9 & 15.876 & 2.056999 & Humulene & 1656 & 1657 \\
10 & 16.373 & 1.516658 & 1-limonene & 1678 & 1679 \\
\hline
\end{tabular}

${ }^{\mathrm{a}}$ Retention time.

${ }^{\mathrm{b}}$ Components are listed in order of their retention time.

${ }^{\mathrm{c}}$ Linear retention index on HP-5 (30 $\mathrm{m} \times 0.25 \mathrm{~mm}, 0.25 \mu \mathrm{l}$ film thickness), experimentally determined using homologous series of $\mathrm{C}_{7-}$ $\mathrm{C}_{40} n$-alkanes.

${ }^{\mathrm{d}}$ Arithmetic retention index on HP-5 (30 m x $0.25 \mathrm{~mm}, 0.25 \mu \mathrm{l}$ film thickness), experimentally determined using homologous series of $\mathrm{C}_{7}-\mathrm{C}_{40} n$-alkanes.

Identification methods: based on comparison with authentic compounds, NIST 08 MS databases; RI, based on comparison of calculated RI with those reported in Adams or NIST 08. 
GC-MS analyses of banana: The GC-MS analyses of volatile components of banana are given in table 3 . Overall, $99.99 \%$ of volatile components were recognized. The major dominating components were cycloheptasiloxane, tetradecamethyl-, phenol, 2-ethyl-6methyl-, tridecane, hexadecane, nonadecane, and tetradecane, which accounts $(64.74 \%)$ of total constitutes. While other minor constitutes, which makeup the balance was filled with following components e.g. menthyl acetate, cyclohexasiloxane, dodecamethyl-,1triethylsilyloxyheptadecane, beta.-curcumene, ethyl chrysanthemate, dodecane, 2-cyclohexyl-, pentadecane, 4-methyl-, cedrol, pentadecane, cyclooctasiloxane, hexadecamethyl-, heptadecane, pentadecane, 2,6,10,14tetramethyl-, cyclononasiloxane, octadecamethyl-, dibutyl phthalate, lupeol, and 1-hydroxypyrene (Table 3).

Table 2. Volatile components from the guava.

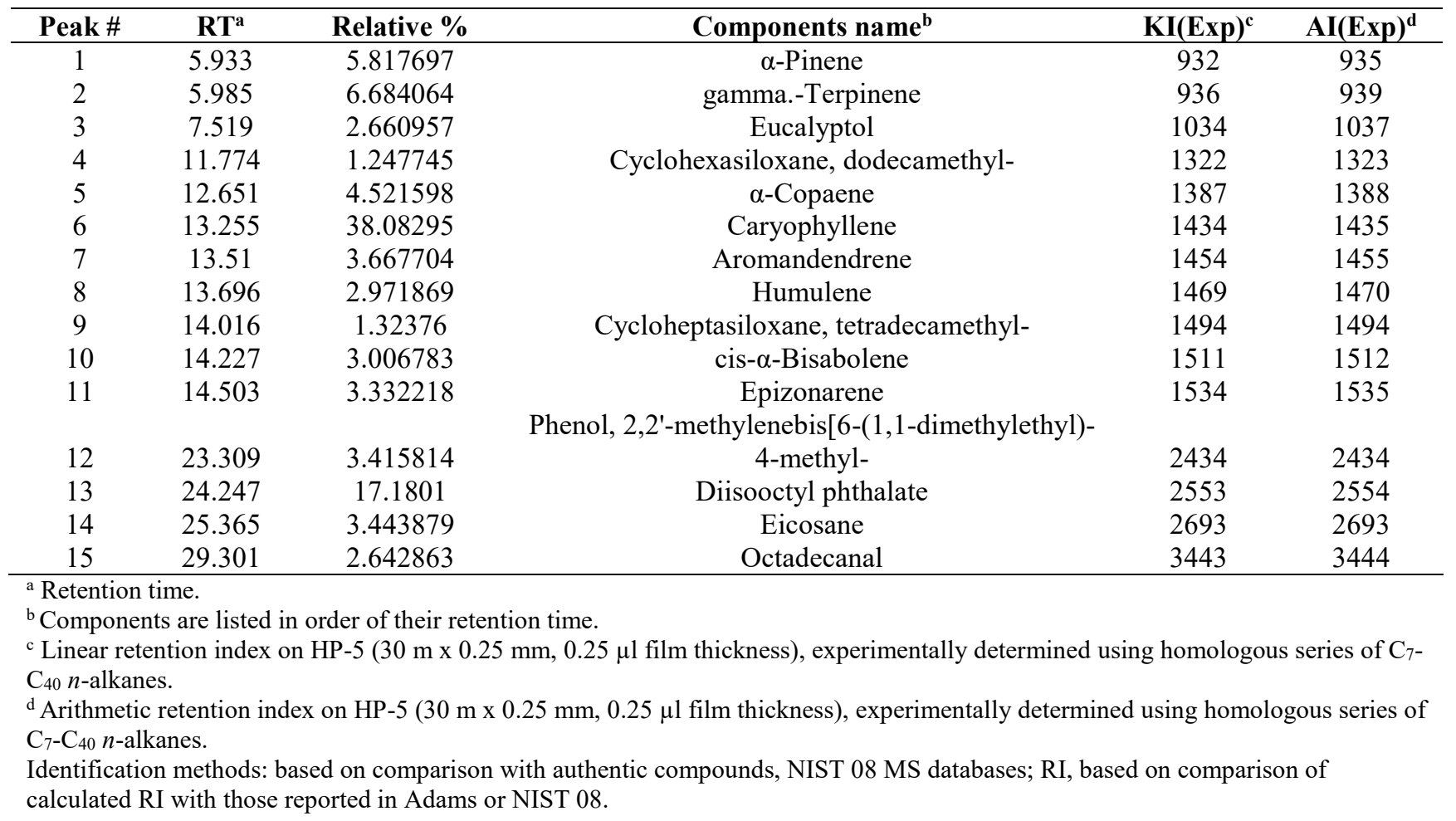

Table 3. Volatile compounds from the banana.

\begin{tabular}{|c|c|c|c|c|c|}
\hline Peak \# & RT $^{\mathbf{a}}$ & Relative \% & Components name ${ }^{b}$ & $\mathrm{KI}(\operatorname{Exp})^{\mathrm{c}}$ & $\operatorname{AI}(\operatorname{Exp})^{d}$ \\
\hline 1 & 11.155 & 0.846196 & Menthyl acetate & 1278 & 1279 \\
\hline 2 & 11.236 & 3.951046 & Cyclohexasiloxane, dodecamethyl- & 1283 & 1284 \\
\hline 3 & 11.312 & 3.218066 & 1-Triethylsilyloxyheptadecane & 1289 & 1289 \\
\hline 4 & 11.335 & 1.695342 & Trimethylsilylestrone & 1290 & 1291 \\
\hline 5 & 12.296 & 4.00518 & Tetradecane & 1361 & 1362 \\
\hline 6 & 12.343 & 6.014059 & Hexadecane & 1364 & 1366 \\
\hline 7 & 12.753 & 1.4022 & beta.-curcumene & 1395 & 1395 \\
\hline 8 & 12.957 & 10.2603 & Phenol, 2-ethyl-6-methyl- & 1411 & 1411 \\
\hline 9 & 13.04 & 2.58074 & Ethyl chrysanthemate & 1417 & 1418 \\
\hline 10 & 13.128 & 6.297894 & Nonadecane & 1424 & 1425 \\
\hline 11 & 13.581 & 29.51357 & Cycloheptasiloxane, tetradecamethyl- & 1460 & 1461 \\
\hline 12 & 14.299 & 3.560385 & Dodecane, 2-cyclohexyl- & 1517 & 1518 \\
\hline 13 & 14.374 & 1.760229 & Pentadecane, 4-methyl- & 1524 & 1524 \\
\hline 14 & 14.809 & 8.604666 & Tridecane & 1560 & 1561 \\
\hline 15 & 15.119 & 1.546458 & Cedrol & 1586 & 1586 \\
\hline 16 & 15.378 & 2.174767 & Pentadecane & 1608 & 1608 \\
\hline
\end{tabular}




\begin{tabular}{llcccc}
17 & 15.591 & 3.698298 & Cyclooctasiloxane, hexadecamethyl- & 1626 & 1627 \\
18 & 15.951 & 1.47192 & Heptadecane & 1658 & 1659 \\
19 & 16.023 & 1.523668 & Pentadecane, 2,6,10,14-tetramethyl- & 1664 & 1665 \\
20 & 17.329 & 1.23439 & Cyclononasiloxane, octadecamethyl- & 1783 & 1784 \\
21 & 17.814 & 1.436389 & Dibutyl phthalate & 1830 & 1830 \\
22 & 24.584 & 2.167665 & Lupeol & 2597 & 2597 \\
23 & 24.615 & 1.036568 & 1-Hydroxypyrene & 2601 & 2601 \\
\hline
\end{tabular}

a Retention time.

${ }^{\mathrm{b}}$ Components are listed in order of their retention time.

${ }^{\mathrm{c}}$ Linear retention index on HP-5 (30 m x $0.25 \mathrm{~mm}, 0.25 \mu \mathrm{l}$ film thickness), experimentally determined using homologous series of $\mathrm{C}_{7-}$ $\mathrm{C}_{40} n$-alkanes.

${ }^{\mathrm{d}}$ Arithmetic retention index on HP-5 (30 m x $0.25 \mathrm{~mm}, 0.25 \mu \mathrm{l}$ film thickness), experimentally determined using homologous series of $\mathrm{C}_{7}-\mathrm{C}_{40} n$-alkanes.

Identification methods: based on comparison with authentic compounds, NIST 08 MS databases; RI, based on comparison of calculated RI with those reported in Adams or NIST 08.

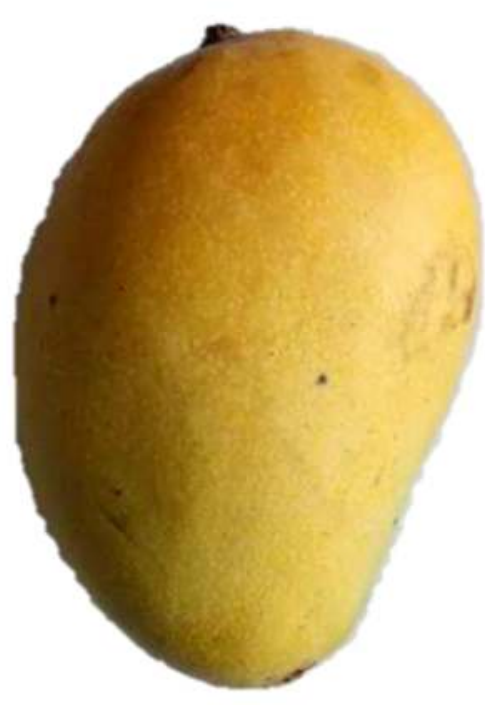

a

Figure 1. Different fruit.

a. mango, b. guava, c. banana.

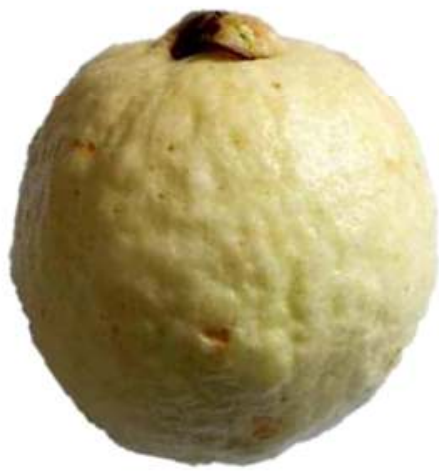

b

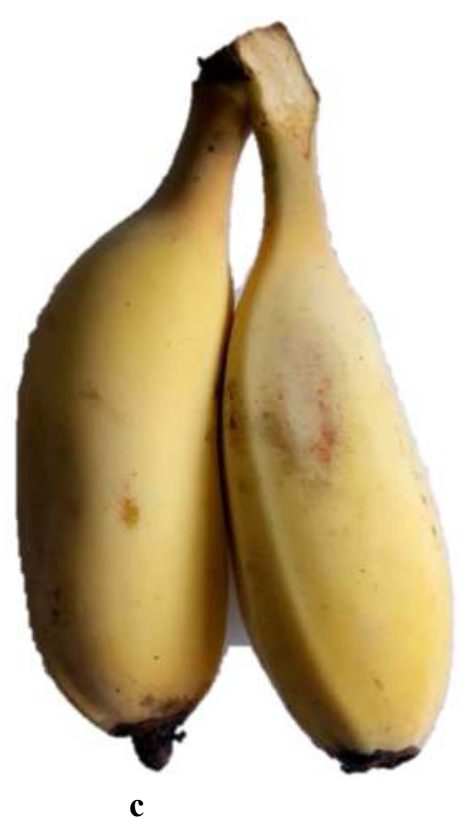

c

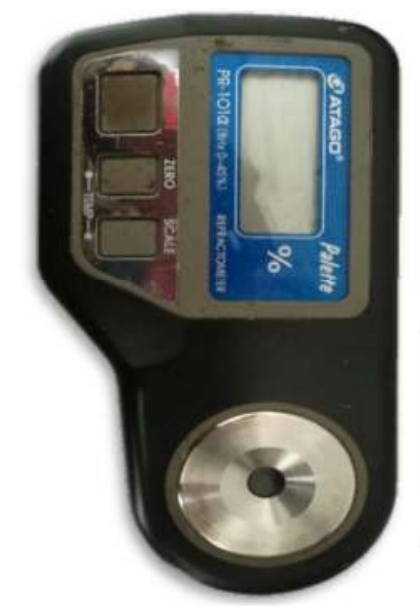

(a)

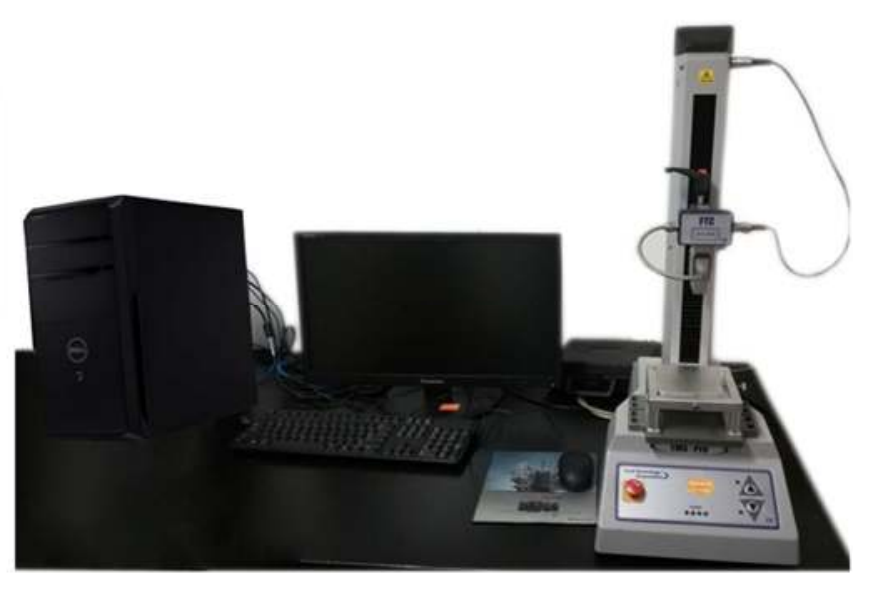

(b)

Figure 2. Handheld pocket refractometer (a) and TMS-Pro texture analyzer (b). 


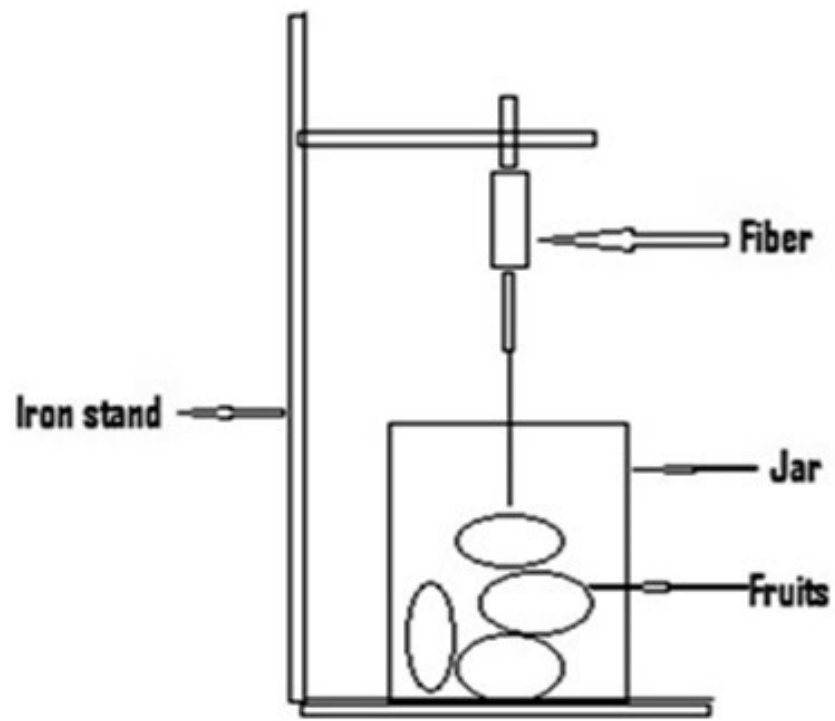

Figure 3. Schematic diagram for the collection of volatile components/compounds from the fruits by solid-phase micro-extraction (SPME).

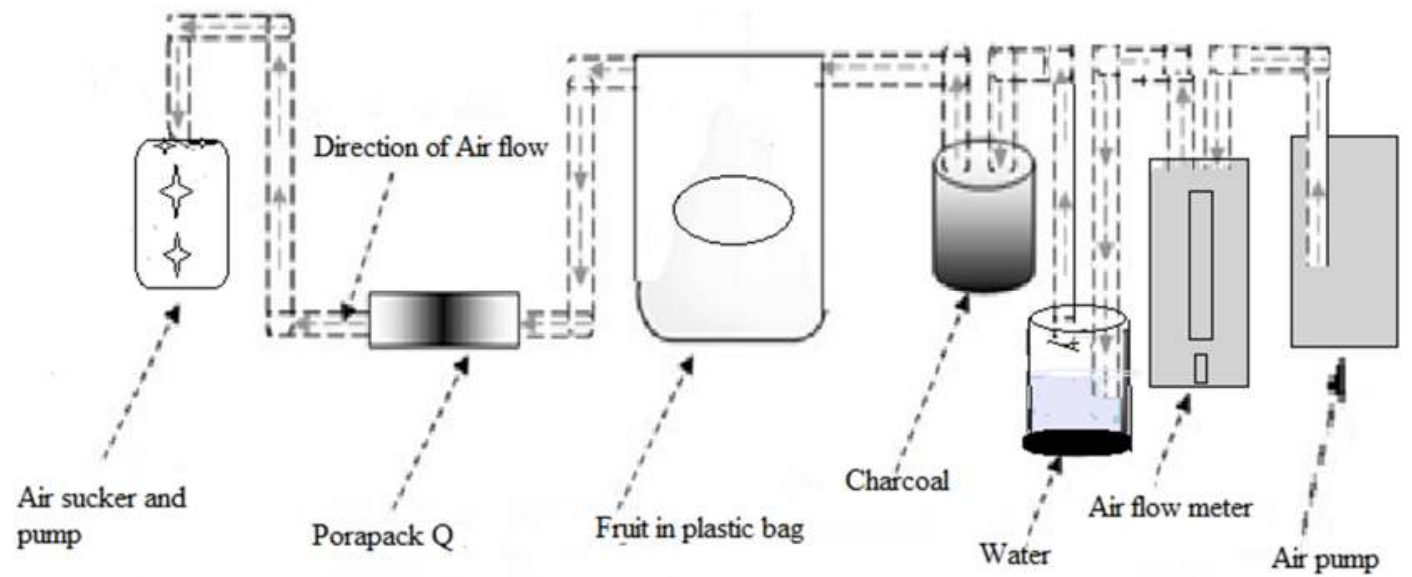

Figure 4. Schematic diagram for the collection of volatile components/compounds from the fruits by using porapak Q.

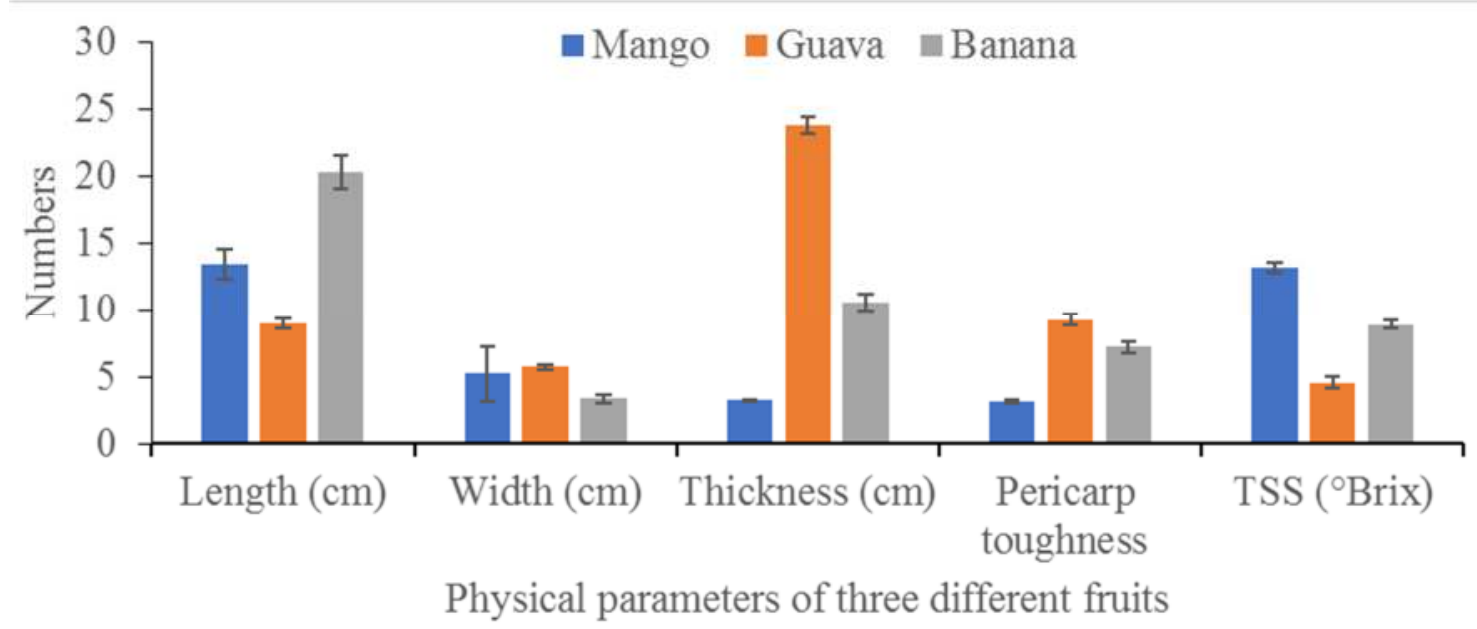

Figure 5. Mean ( \pm SE) of physicochemical properties of mango, guava, and banana fruits $(n=15)$. 


\section{DISCUSSION}

Volatile or aromatic compounds can vary among fruit cultivars (Zhu et al., 2018). Volatile components of fruit are very important for taste (Jayanthi et al., 2012; Malo et al., 2012; Song et al., 2019). The predominant volatile components were determined in the Coche mango e.g. 3-carene, b-selinene, terpinolene, and limonene (Malo et al., 2012; Jimenez et al., 2019). The 3carene is major aromatic compound in mango fruits and pulp (Tamura et al., 2000; Wetungu et al., 2018) and also important attractive components for insect pests (Jaleel et al., 2019). The 3-carene was major constitute in mango among other constitutes e.g. acetic, butyric and hexanoic acids; and ethyl 3-hydroxybutyrate (Ghatak et al., 2018). Thirteen volatiles components were reported in mango using GCMS e.g. acetaldehyde, acetone, methanol, ethanol, a-pinene, caryophyllene, 3-carene, b-pinene, myrcene, limonene, terpinolene, a-copaene, and r-cymene (Baldwin et al., 1999; Pino and Mesa, 2006; MaldonadoCelis et al., 2019). In our study, 3-carene, $\alpha$-pinene, and butyl caprylate were the main volatile components in mango odors. Each volatile component has a specific aroma to call or repel the insect pests (Jang and Light, 1991; Jaleel et al., 2018a; Jaleel et al., 2018c). Volatile components of fruits are very important to attract the female adults of insect pests (Jaleel et al., 2018b). 3carene, caryophyllene, and humulene were reported main volatile components in guava fruits (McQuate et al., 2017). In our study, caryophyllene, $\alpha$-pinene, gamma.terpinene, and $\alpha$-copaene were the main volatile components in the order of guava fruit. Schwab et al. (2008) reported the major portion of 3-methyl butyl acetate, isoamyl butanoate, and isoamyl isovalerate in banana fruits. And concluded that, the 3-methyl-1-methyl hexyl-2- methyl propyl or isobutyl: 3-methyl butyl or isoamyl: and hexyl esters of acetic, butanoic, and isovaleric acids are the main source of aroma in banana fruits (Wetungu et al., 2018; Zhu et al., 2018). Butyl acetate, isoamyl acetate, ethyl acetate, butyl butanoate, and isoamyl isobutanoate were main components in banana fruit (Zhu et al., 2018; Zhang et al., 2019). In our study, cycloheptasiloxane, tetradecamethyl-, Phenol, 2ethyl-6-methyl-, Tridecane, Hexadecane, Nonadecane, and Tetradecane were the major portion of aromatic or volatile components in banana fruits. In conclusion, the main major constitution of volatile component obtained mango, guava, and banana was 3-carene, caryophyllene, and cycloheptasiloxane, tetradecamethyl- respectively.

Acknowledgments: This research was supported by the National Key Research and Development Program of China (2018YFD0201300), the Guangdong Provincial Special Fund for Modern Agriculture Industry Technology Innovation Teams, Department of Agriculture and Rural Affairs of Guangdong Province
(No. 2019KJ125), the Innovation Team of Modern Agricultural Industry Generic Key Technology R and D of Guangdong Province (2019KJ134), the National Key R and D Program of China (2017YFC1200600), and the Open Fund of the Guangxi Key Laboratory of Biology for Crop Diseases and Insect Pests, China (2016-KF-3). The funders had no role in study design, data collection and analysis, decision to publish, or preparation of the manuscript.

\section{REFERENCES}

Alagarmalai, J., Nestel. D, Dragushich. D, Nemny-Lavy. E, Anshelevich. L, Zada. A and Soroker. V (2009). Identification of host attractants for the Ethiopian fruit fly, Dacus ciliatus Loew. J. Chem. Ecol. 35: 542-551.

Ali, S., Li. S, Jaleel. W, Khan. M. M, Wang. J and Zhou. X (2020). Using a Two-Sex Life Table Tool to Calculate the Fitness of Orius strigicollis as a Predator of Pectinophora gossypiella. Insects. 11(5): 275.

Arvanitoyannis, I. and Mavromatis. A (2009). Banana cultivars, cultivation practices, and physicochemical properties. Crit. Rev. Food Sci. Nutr. 49: 113-135.

Asif, M. and Kaur. A (2018). Biologically active phytochemical contents and biological activities of whole Musa acuminata (BANANA) plant. IJRAMPR 1: 5-33.

Baldwin, E. A., Burns. J. k, Kazokas. W, Brecht. J. K, Hagenmaier. R. D, Bender. R. J and Pesis. E (1999). Effect of two edible coatings with different permeability characteristics on mango (Mangifera indica L.) ripening during storage. Postharvest. Biol. Tec. 17: 215-226.

Biasazin, T. D., Karlsson. M. F, Hillbur. Y, Seyoum. E and Dekker. T (2014). Identification of host blends that attract the African invasive fruit fly, Bactrocera invadens. J. Chem. Ecol. 40: 966976.

Bodini, R. B., Montini. E. M, de Carvalho. C. C, de Moraes L. A, Meirelles. A. J. D. A and de Oliveira. A. L (2019). Sensory and Composition Analyses of the Aqueous Phases from the Concentration of Guava (Psidium Guava L.) and Mango (Mangifera Indica L.) Juices and the Process-Induced Losses of Vitamin C. 11. The Open Food Sci J. 12:44-55

Cruz-López, L., Malo. E. A, Toledo. J, Virgen. A, Del Mazo. A and Rojas. J. C (2006). A new potential attractant for Anastrepha obliqua from Spondias mombin fruits. J. Chem. Ecol. 32: 351-365.

Damodaram, K. J. P., Aurade. R. M, Kempraj. V, Roy. T. K, Shivashankara. K. S and Verghese. A (2015). Salicylic acid induces changes in mango fruit 
that affect oviposition behavior and development of the oriental fruit Fly, Bactrocera dorsalis. Plos One. 10: e0139124.

Deo, A. and Shastri. N. V (2003). Purification and characterization of polygalacturonase-inhibitory proteins from Psidium guajava Linn. (guava) fruit. Plant Sci. 164: 147-156.

El-Sayed, A. M., Suckling. D. M, Byers. J. A, Jang. E. B and Wearing. C. H (2009). Potential of "lure and kill" in long-term pest management and eradication of invasive species. J. Econ. Entomol. 102: 815-835.

FAO, F. J. L. P. F (2016). Agriculture Organization, 2014. Food Agriculture Organization of the United Nations.

FAO, I (2017) W. F. P. The State of Food Insecurity in the World, 2014. Strengthening the enabling environment for food security and nutrition.

Forister, M. L., Novotny. V, Panorska. A. K, Baje. L, Basset. Y, Butterill. P. T, Cizek. L, Coley. P. D, Dem. F, Diniz. I. R and Drozd. P (2015). The global distribution of diet breadth in insect herbivores. Procee. Nat. Acad. Sci. 112: 442447.

Galal, O., Galal. H and Aboulila. A (2017). Genetic variability and molecular characterization of some local and imported mango cultivars in Egypt. Egyptian J Genetics Cytology. E. J. G and Cytology. 46: 121-138.

Gautam, I. P. and Gotame. T. P (2020). Diversity of Native and Exotic Fruit Genetic Resources in Nepal. 6: 44-55. JNARC.

Ghatak, B., Ali. S. B, Prasad. A, Ghosh. A, Sharma. P, Tudu. B, Pramanik. P and Bandyopadhyay. R (2018). Application of polymethacrylic acid imprinted quartz crystal microbalance sensor for detection of 3-Carene in mango. IEEE Sensors. 18: 2697-2704.

Girard, B., Kopp. T. G, Reynolds. A. G and Cliff. M (1997). Influence of vinification treatments on aroma constituents and sensory descriptors of Pinot noir wines. Am. J. Enol. Viticult. 48: 198206.

Jaleel, W., He. Y and Lu. L (2019). The response of two Bactrocera species (Diptera: Tephritidae) to fruit volatiles. J. Asia. Paci. Entomol. 22: 758765.

Jaleel, W., Lu. L and He. Y (2018a). Biology, taxonomy, and IPM strategies of Bactrocera tau Walker and complex species (Diptera; Tephritidae) in Asia: a comprehensive review. Environ. Sci. Pollut. Res. 25: 19346-19361.

Jaleel, W., Yin. J, Wang. D, He. Y, Lu. L and Shi. H (2018b). Using two-sex life tables to determine fitness parameters of four Bactrocera species
(Diptera: Tephritidae) reared on a semi-artificial diet. Bull. Entomol. Res. 107: 707-714.

Jaleel, W., Tao. X, Wang. D, Lu. L, and He. Y (2018c). Using Two-Sex Life Table Traits to Assess the Fruit Preference and Fitness of Bactrocera dorsalis (Diptera: Tephritidae). J. Eco. Entomol. 111(6): 2936-2945.

Jaleel W., Wang. D, Lei. Y, Qi. G, Chen. T, Rizvi. S. A. H, Sethuraman. V, He. Y and Lu. L (2020). Evaluating the repellent effect of four botanicals against two Bactrocera species on mangoes. PeerJ. e8537

Jang, E. B. and Light. D. M (1991). Behavioral responses of female oriental fruit flies to the odor of papayas at three ripeness stages in a laboratory flight tunnel (Diptera: Tephritidae). J. Insect Behav. 4: 751-762.

Jayanthi, P. D. K., Kempraj. V, Aurade. R. M, Venkataramanappa. R. K, Nandagopal. B, Verghese. A and Bruce. T. J (2014). Specific volatile compounds from mango elicit oviposition in gravid Bactrocera dorsalis females. J. Chem. Ecol. 40: 259-266.

Jayanthi, P. D. K., Woodcock. C. M, Caulfield. J, Birkett M. A and Bruce. T. J (2012). Isolation and identification of host cues from mango, Mangifera indica, that attract gravid female oriental fruit fly, Bactrocera dorsalis. J. Chem. Ecol. 38: 361-369.

Jimenez, L. F. J., Barros. A. H and De Ávila Z. I. C (2019). Synthesis and characterization of Fe55Co45 magnetic nanoparticles by polyol and green chemistry method. R. Phy. 15: 102785.

Jordán, M. J., Tandon. K, Shaw. P. E and Goodner. K. L (2001). Aromatic profile of aqueous banana essence and banana fruit by gas chromatography- mass spectrometry (GC-MS) and gas chromatography- olfactometry (GC-O). J. Agric. Food Chem. 49: 4813-4817.

Joseph, B and Priya. M (2011). Review on nutritional, medicinal and pharmacological properties of guava (Psidium guava Linn.). Int. J. Pharma Bio. Sci. 2: 53-69.

Kondo, T (2018). Disintegrable capsule, manufacturing method for same, and smoking device containing said disintegrable capsule: Google Patents.

MacLeod, A. J., and Pieris. N. M (1984). Comparison of the volatile components of some mango cultivars. Phytochem. 23: 361-366.

Maldonado-Celis. M. E., Yahia. E. M, Bedoya. R, Landázuri. P, Loango. N, Aguillón. J, Restrepo. B and Ospina J. C. J (2019). Chemical composition of mango (Mangifera indica L.) fruit: nutritional and phytochemical compounds. F. P. Sci. 10 . 
Malo, E. A., Gallegos. Torres. I, Toledo. J, Valle-Mora. J and Rojas. J. C (2012). Attraction of the West Indian fruit fly to mango fruit volatiles. Entomol. Exp. Appl. 142: 45-52.

McQuate, G. T., Sylva. C. D and Liquido. N. J (2017). Natural field infestation of Mangifera casturi and Mangifera lalijiwa by oriental fruit fly, Bactrocera dorsalis (Diptera: Tephritidae). Int. J. Insect Sci. 9: 1179543317717735.

Mitra, S. K (2014). Mango production in the worldpresent situation and future prospect. $X X I X$ International Horticultural Congress on Horticulture: Sustaining Lives, Livelihoods and Landscapes (IHC2014): IV 1111. 287-296.

Paniandy, J. C., Chane-Ming. J and Pieribattesti J. C (2000). Chemical composition of the essential oil and headspace solid-phase microextraction of the guava fruit (Psidium guajava L.). J. Essent. Oil Res. 12: 153-158.

Pino, J. A and Febles. Y (2013). Odour-active compounds in banana fruit cv. Giant Cavendish. Food Chem. 141: 795-801.

Pino, J. A and Mesa. J (2006). Contribution of volatile compounds to mango (Mangifera indica L.) aroma. Flavour Fragr. J. 21: 207-213.

Rodríguez, A., Alquézar. B and Peña. L (2013). Fruit aromas in mature fleshy fruits as signals of readiness for predation and seed dispersal. $\mathrm{N}$. Phy. 197: 36-48.

Sakho, M., Crouzet. J and Seck. S (1985). Volatile components of African mango. J Food Sci. 50: 548-550.

Schwab, W., Davidovich-Rikanati. R and Lewinsohn. E (2008). Biosynthesis of plant - derived flavor compounds. The Plant J. 54: 712-732.

Shaw, P. E (2017). Fruits ii: Volatile compounds in foods and beverages (ed. Routledge, pp. 305-327.

Shen, S. C., Cheng. F. C and Wu. N. J (2008). Effect of guava (Psidium guajava Linn.) leaf soluble solids on glucose metabolism in type 2 diabetic rats. Phytother. Res. 22: 1458-1464.

Sial, M., Saeed. Q, Saeed. S, Jaleel. W, Naqqash. M. N and Majeed. F (2015). Susceptibility of Mango cultivars against larvae of Mango midge Procontarinina mangicola Shi (Cecidomyiidae: Diptera). Appl. Sci. Business Eco. 2: 1-7.

Siderhurst, M. S. and Jang. E. B (2006). Female-biased attraction of oriental fruit fly, Bactrocera dorsalis (Hendel), to a blend of host fruit volatiles from Terminalia catappa L. J. Chem. Ecol. 32: 2513-2524.

Siderhurst, M. S. and Jang. E. B (2010). Cucumber volatile blend attractive to female melon fly, Bactrocera cucurbitae (Coquillett). J. Chem. Ecol. 36: 699-708.
Singh, K. K. and Singh. S. P (2018). A review: Micropropagation of guava (Psidium spp.). J. P and Phytochem. 7: 145-150.

Song, J., Bi. J, Chen. Q, Wu. X, Lyu. Y and Meng. X (2019). Assessment of sugar content, fatty acids, free amino acids, and volatile profiles in jujube fruits at different ripening stages. Food Chem. 270: 344-352.

Souza, J. M., Leonel. S, Modesto. J. H, Ferraz. R. A and Gonçalves. B. H (2018). Fruit Physicochemical and Antioxidant Analysis of Mango Cultivars under Subtropical Conditions of Brazil. J. A S and Technology. 20: 321-331.

Tamura, H., Boonbumrung. S, Yoshizawa. $\mathrm{T}$ and Varanyanond. W (2000). Volatile components of the essential oils in the pulp of four yellow mangoes (Mangifera indica L.) in Thailand. Food. Sci. Tech. Res. 6: 68-73.

Vithana, M. D. K., Singh. Z and Johnson. S. K (2018). Levels of terpenoids, mangiferin and phenolic acids in the pulp and peel of ripe mango fruit influenced by pre-harvest spray application of FeSO 4 (Fe 2+), MgSO 4 ( Mg 2+) and $\mathrm{MnSO}$ 4 (Mn 2+). Food Chem. 256: 71-76.

Wetungu, M. W., Omolo. M. V, Tarus. P. K and Segor. F. K (2018). Volatile aroma chemical constituents of fruit pulp of some Kenyan varieties of mango (Mangifera indica L.). A. J. E. O and N Products. 6: 29-36.

Xiao-Wei, M. A., Yang. Y. D, Hong-Xia. W. U, Zhou. Y. G and Wang. S. B (2016). Diversity Analysis of Volatile in Mature Fruits of Mango Germplasm. Acta Horti. Sinica. 43: 1267-1274.

Xu, C., Liang. Z, Tang. D, Xiao. T, Tsunoda. M, Zhang. Y, Zhao. L, Deng. S and Song. Y (2017). Gas Chromatography-Mass Spectrometry (GC-MS) Analysis of Volatile Components from Guava Leaves. J. E. O. B. Plants. 20: 1536-1546.

Zahoor, M., Yousaf. Z, Aqsa. T, Haroon. M, Saleh. N, Aftab. A, Javed. S, Qadeer. M, and Ramazan. H (2017). An ethnopharmacological evaluation of Navapind and Shahpur Virkanin district Sheikupura, Pakistan for their herbal medicines. J. Ethnobiol. Ethnomed. 13: 27.

Zhang, J., Jha. S. K, Liu. C and Hayashi. K (2019). Tracing of Chemical Components of Odor in Peels and Flesh from Ripe Banana on a Daily Basis Using GC-MS Characterization and Statistical Analysis for Quality Monitoring During Storage. Food A. M. 12: 947-955.

Zhu, X., Li. Q, Li. J, Luo. J, Chen. W and Li. X (2018). Comparative study of volatile compounds in the fruit of two banana cultivars at different ripening stages. Molecules. 23: 2456. 